\title{
The DNA and RNA polymerase genes of yeast plasmid pGKL2 are essential loci for plasmid integrity and maintenance
}

\author{
Raffael Schaffrath, Surinder M. Soond and Peter A. Meacock
}

Author for correspondence: Peter A. Meacock. Tel: +44116 2522261. Fax: +441162525101.

Department of Genetics, University of Leicester, University Road, Leicester LE1 7RH, UK

\begin{abstract}
Novel recombinant plasmids derived from the Kluyveromyces lactis killer plasmid $\mathbf{k 2}$ have been constructed to study plasmid biology and gene function. In vivo recombination between native resident $\mathbf{k} 2$ and suitable disruption vectors, employing the KITRP1 gene fused to a plasmid promoter as selection marker, yielded ORF2 and ORF6 deletion plasmids at high frequencies. As judged from Southern hybridization and plasmid restriction mapping analyses, these novel hybrids, termed rk2/2 and rk2/6, respectively, carry deletions in their putative DNA (ORF2) and RNA (ORF6) polymerase structural genes with central regions replaced by the input marker DNA. Long-term selection for TRP1 over $\mathbf{3 5 0}$ generations of growth did not favour maintenance of hybrids over wild-type k2. Thus, neither rk2/2 nor rk2/6 was fully functional and able to displace parental k2, indicating that both target genes are essential for plasmid integrity or maintenance. Recombinant plasmids were reduced in copy number relative to $\mathbf{k} 2$ with rk2/2 more drastically affected than rk2/6 implying a direct involvement of the ORF2 product in plasmid replication and an indirect maintenance function for the ORF6 gene product.
\end{abstract}

Keywords: Kluyveromyces lactis, killer system, linear plasmids, DNA/RNA polymerases, gene disruptions

\section{INTRODUCTION}

Linear DNA plasmids have been identified for various yeast genera such as Debaryomyces, Pichia, Wingea, Kluyveromyces and Saccharomyces and shown to share many common features. They are extremely A + T-rich (Stark et al., 1990; Hishinuma \& Hirai, 1991), partially crosshybridize to each other (Cong et al., 1994; Bolen et al., 1994) and show structural and phylogenetic relatedness to adenovirus in carrying terminal inverted repeats (TIRs) with covalently attached terminal proteins (TPs) (Meinhardt $e$ t al., 1990; Meinhardt \& Rohe, 1993; Stark $e t$ al., 1990; Rohe et al., 1992; Gunge et al., 1993). In terms of gene function, the best-characterized of these yeast episomal systems is the cytoplasmically localized killer plasmid pair, $\mathrm{k} 1$ and $\mathrm{k} 2$, of the dairy yeast Kluyveromyces lactis (for review see Stark et al., 1990). The smaller plasmid k1 (8.9 kb) carries four ORFs (Hishinuma et al., 1984) with gene functions involved in plasmid replication

Abbreviations: g.p.r., generations post-recombination; k1, pGKL1; k2, pGKL2; mcs, multiple cloning site; TIR, terminal inverted repeat; TP, terminal protein; UCS, upstream conserved sequence. and expression of killer and immunity phenotypes (Stark \& Boyd, 1986; Tokunaga et al., 1987). Genetic analysis has shown that plasmid $\mathrm{k} 2(13.5 \mathrm{~kb})$, which carries ten ORFs, provides essential maintenance functions presumably involved in transcription and replication of both plasmids (Stark et al., 1990; Schaffrath \& Meacock, 1995; Schaffrath et al., 1995). Thus, k2 appears to encode an initiation factor for $\mathrm{k} 1 / \mathrm{k} 2$ replication as well as putative helicase and DNA/RNA polymerases (McNeel \& Tamanoi, 1991; Tommasino, 1991; Tommasino et al., 1988; Wilson \& Meacock, 1988; Stark et al., 1990). Upstream conserved sequence (UCS) motifs preceding all plasmid genes have been shown to possess promoter activity and have been exploited for gene disruption analysis. In fact $k 1 / k 2$-targeted integration of foreign DNA was only possible when markers, i.e. Saccharomyces cerevisiae LEU2 and Eschericbia coli $\operatorname{Tn} 903$-derived $G 418^{\mathrm{R}}$, were transplaced as UCS-fusion genes. Like native $\mathrm{k} 1$ and $\mathrm{k} 2$, the resulting hybrids exhibited identical characteristics in having a linear structure with TPs attached, cytoplasmic location and high stability (Kämper et al., 1991; TanguyRougeau et al., 1990; Schaffrath et al., 1992). This allelic replacement procedure in vivo has proven useful for the study of both basic and applied aspects of linear plasmid 
biology. In this manner, $\mathrm{k} 1 \mathrm{ORF} 2$ and $\mathrm{k} 2 \mathrm{ORF} 1$ have been identified as dispensable genes (Kämper et al., 1991; Schaffrath et al., 1992) and potential loci for heterologous gene expression (Meinhardt et al., 1994). Here, we report a gene-disruption analysis of two $\mathrm{k} 2$ genes, the putative DNA and RNA polymerase genes ORF2 and ORF6, respectively, using a UCS-TRP1 fusion marker and show both loci to be essential for plasmid integrity and/or maintenance.

\section{METHODS}

Strains, plasmids and general methods. All strains and plasmids used and generated in the course of this study are listed in Tables 1 and 2. Basic yeast methods and growth media, YPD and SD, were as described by Sherman (1991). Yeast transformations were carried out according to Gietz et al. (1992) using $5 \mu \mathrm{g}$ transfer vectors pAR5 and pMS202/600 completely digested as indicated to release recombination cartridges (Fig. 1). Routine bacterial growth conditions and recombinant DNA methodology were adopted from Sambrook et al. (1989). DNA sequence was determined by the dideoxy method (Sanger et al., 1977) using the T7 Sequencing kit (Pharmacia). Standard PCRs were carried using synthetic oligonucleotide primers (see below), all four dNTPs at $0.2 \mathrm{mM}$ each and Vent DNA polymerase (New England Biolabs) according to the supplier's instructions. Synthetic oligonucleotides were: $k 2$ pos. $10723-$ 10740 (Tommasino et al., 1988), FW6 5' GGATCCAGAAATAGGTAAAGTAAC 3' (k2ORF6); and k2 pos. 1128011299, FW7 5' CATATGAATGAAAATATTAT'T'TC 3' (k2ORF7).

\section{Construction of k1- and k2-targeted disruption vectors}

pAR5. Prior to the construction of $\mathrm{k} 2$-gene targeting vectors, plasmid pAR5 was generated for specific disruption of k1ORF2 in control experiments. In pAR5 the $1.6 \mathrm{~kb}$ ScLEU2 gene fragment of pAR4 (J. Schründer \& F. Meinhardt, personal communication) was replaced by the $0.7 \mathrm{~kb} N$ si I/Bam $\mathrm{HI}$ KITRP1 gene fragment of pSS9 (S. M. Soond \& P. A. Meacock, unpublished). For convenience, the external pUCbased HindIII site was converted into an $N$ heI site by restriction,
Klenow fill-in and re-ligation (Fig. 1a). Thus, digestion of pAR5 with $N$ heI and EcoRI releases the k1ORF2 disruption cassette for yeast transformation experiments.

pMS600. Plasmid pMS600, a targeting vector for disruption of k2ORF6, was constructed as follows. A $0.8 \mathrm{~kb} N c o l$ k2 fragment, obtained from $\mathrm{pRS} 23$, a $\mathrm{k} 2$ subclone derived from pGKF202, was cloned into the single NcoI site of pUCBM21. In the resultant pRS27, this k2 segment (pos. 7317-8060, Tommasino et al., 1988) carries ORF5 and a short 5' ORF6 region representing the 26 amino terminal residues of the putative RNA polymerase. This ORF6 segment was flanked downstream by the $1.9 \mathrm{~kb}$ Pst $/$ BamHI k1UCS2-LEU2 fusion gene from pRS1 to give pRS36. The use of template pGKF202 and primers FW6/7 (see above) in PCR yielded a second $0.6 \mathrm{~kb}$ k2 fragment which was subcloned into SmaI-cut pUC13 (pRS16). This $\mathrm{k} 2$ fragment carries the complete ORF7 and the $3^{\prime}$ terminal $0 \cdot 2 \mathrm{~kb}$ of ORF6 (k2 pos. 10723-10906, Tommasino et al., 1988). Subcloning this fragment into BamHI-restricted pRS36 generated the vector pMS60. Finally, pMS600 was constructed by replacement of the ScLEU2 marker with the KITRP1 gene from pAR5. Thus, in pMS600 the k1UCS2 element is fused in-phase to TRP1. Allelic replacement of k2ORF6 will occur when yeast cells are transformed with pMS600 digested with HindIII and NdeI (Fig. 1b).

pMS202. Plasmid pMS202, a targeting vector for disruption of k2ORF2, was constructed as follows. Replacement of the k2 sequence of pRS36, excised with HindIII and Pst $\mathrm{I}$, with a terminal $1.0 \mathrm{~kb} H$ indIII/Nsi fragment of pICk2S (Table 2) resulted in $\mathrm{pRF} 1$. The $\mathrm{k} 2$ segment of $\mathrm{pRF} 1$ carries $\mathrm{k} 2 \mathrm{ORF} 1$ preceded by a partial TIR sequence and the $3^{\prime}$ terminal $0.2 \mathrm{~kb}$ of k2ORF2 (k2 pos. 117-1106). pRF2 was generated by replacing the ScLEU2 marker with the KITRP1 gene from PAR5 as outlined above. Part of the ampicillin resistance gene of pRF2 was released upon $S \mathrm{maI} / \mathrm{ScaI}_{\mathrm{I}}$ double restriction and functionally reconstituted with the $3.3 \mathrm{~kb}$ ScaI fragment of pICk2S to give pMS200. This second $\mathrm{k} 2$ segment contains almost all of ORF3 ( $\mathrm{k} 2$ pos. 3889-5655) and the $5^{\prime}$ terminal $0.7 \mathrm{~kb}$ region of ORF2 ( $\mathrm{k} 2$ pos. 3221-5655, Tommasino et al., 1988). Thus, the disruption cartridge of pMS202 released by HindIII digestion was expected to promote in vivo recombination and allelic replacement of ORF2 by the TRP1 marker gene (Fig. 1c).

Table 1. Strains

\begin{tabular}{|c|c|c|}
\hline Strain & Description & Source \\
\hline \multicolumn{3}{|l|}{ E. coli } \\
\hline NM522 & $\begin{array}{l}\Delta(\text { lac-pro } A B) \text { thi supE } \Delta\left(\text { bsdMS-mcrB) } 5 \mathrm{r}_{\mathrm{K}}^{-} \mathrm{m}_{\mathrm{K}}^{-}\right. \\
m c r B / \mathrm{F}^{\prime}\left(\text { pro } A B^{+} \text {lac } \mathrm{I}^{\mathrm{q}} \text { lac } \mathrm{M} \Delta \mathrm{M} 15\right)\end{array}$ & Gough \& Murray (1983) \\
\hline \multicolumn{3}{|l|}{ K. lactis } \\
\hline AWJ137 & $\alpha$ leu2 $\operatorname{trp} 1\left(\mathrm{k} 1^{+} \mathrm{k} 2^{+}\right)$(killer, immune) & Kämper et al. (1991) \\
\hline SD801 & a $\operatorname{trp} 1$ lac $4\left(\mathrm{k} 1^{0} \mathrm{k} 2^{0}\right)$ (non-killer, sensitive) & Stark \& Milner (1989) \\
\hline KRS13 & $\begin{array}{l}\alpha \operatorname{leu} 2 \operatorname{trp} 1\left[\mathrm{k} 1^{+} \mathrm{pRKL} 2(\mathrm{k} 2 \Delta \mathrm{ORF} 1:: \mathrm{k} 1 \mathrm{UCS} 2\right. \\
\text { ScLEU2)] (killer, immune) }\end{array}$ & Schaffrath et al. (1992) \\
\hline MS1 & $\begin{array}{l}\alpha \text { leu2 } \operatorname{trp} 1\left[\mathrm{pRKL} 1(\mathrm{k} 1 \Delta \mathrm{ORF} 2: \mathrm{KlTRP} 1) \mathrm{k} 1^{+}\right. \\
\left.\mathrm{k} 2^{+}\right] \text {(killer, immune) }\end{array}$ & This work \\
\hline NKMS1 & $\alpha$ leu $2 \operatorname{trp} 1\left[\mathrm{pRKL} 1 \mathrm{k} 2^{+}\right]$(non-killer, immune) & This work \\
\hline MS20 & $\begin{array}{l}\alpha \text { leu2 } \operatorname{trp} 1\left[\mathrm{k} 1^{+} \mathrm{k} 2^{+} \mathrm{rk} 2 / 2(\mathrm{k} 2 \Delta \mathrm{ORF} 2:: \mathrm{k} 1 \mathrm{UCS} 2\right. \\
\mathrm{K} 1 T R P 1) \text { (killer, immune) }\end{array}$ & This work \\
\hline MS60 & $\begin{array}{l}\alpha \text { leu2 } \operatorname{trp} 1\left[\mathrm{k} 1^{+} \mathrm{k} 2^{+} \mathrm{rk} 2 / 6(\mathrm{k} 2 \Delta \mathrm{ORF} 6: \mathrm{k} 1 \mathrm{UCS} 2\right. \\
\mathrm{KITRP} 1) \text { (killer, immune) }\end{array}$ & This work \\
\hline
\end{tabular}


Table 2. Plasmids

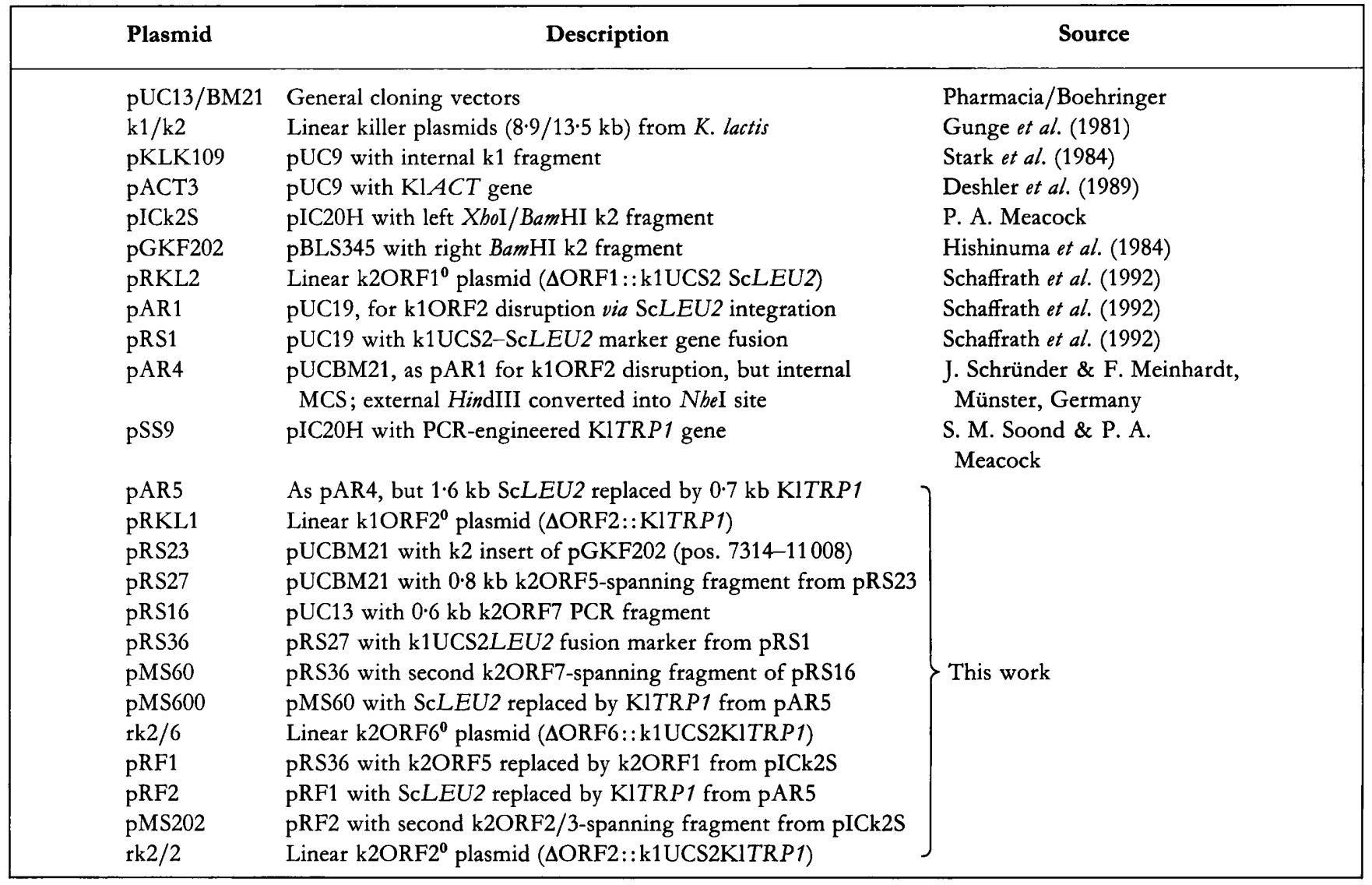

DNA preparations, yeast plasmid mapping and Southern hybridization. E. coli plasmid DNA was isolated by alkaline lysis (Sambrook et al., 1989). Rapid preparations of $K$. lactis linear plasmid DNAs for screening transformants, and highquality linear plasmid DNA preparations for restriction mapping and Southern blot analysis were performed as reported by Schaffrath \& Meacock (1995). High-specific-activity labelling of DNA probes was carried out by random hexamer priming (Feinberg \& Vogelstein, 1983) using [ $\left.\alpha^{-}{ }^{32} \mathrm{P}\right] \mathrm{dCTP}$ ( $>3000 \mathrm{Ci} \mathrm{mmol}^{-1}$; > $111 \mathrm{TBq} \mathrm{mmol}^{-1}$; Amersham). Radiolabelled probes were prepared from the following restriction fragments: Kl $A C T, 0.3 \mathrm{~kb} B g / \mathrm{II}$ from pACT3; KlTRP1, $0.7 \mathrm{~kb}$ $N s i$ /BamHI from pAR5; k1ORF2, $2.3 \mathrm{~kb} N s i \mathrm{I}$ from pKLK109; k1ORF3, 0.6 kb Bg/II/EcoRI from pAR5; k1UCS2, $0.3 \mathrm{~kb}$ PstI/NsiI from pRS1; k2ORF2, $1.5 \mathrm{~kb} N s i \mathrm{I}$ from pICk2S; k2ORF4, $1.7 \mathrm{~kb}$ BamHI/SnaBI from pGKF202; k2ORF6, $2.7 \mathrm{~kb} \mathrm{NcoI/NdeI} \mathrm{from} \mathrm{pGKF202} \mathrm{(see} \mathrm{Table} \mathrm{2).} \mathrm{For}$ plasmid copy analysis, the strengths of k1UCS2 and k2ORF4 hybridization signals of recombinant plasmids, standardized to the values found for wild-type plasmids, were quantified using a Molecular Dynamics Phosphor-Imager.

RNA isolation and Northern analysis. Total RNA isolation and Northern analysis was performed as described by Schaffrath \& Meacock (1995). DNA/RNA hybridization involved k2ORF2/ORF6 and $A C T$ gene probes (see above).

Plasmid functional analysis. Plasmid segregation analysis was carried out by sequential $\operatorname{Trp}^{+}$selective subcultivation of transformant strains over 350 generations in minimal SD medium supplemented with $40 \mu \mathrm{g}$ leucine $\mathrm{ml}^{-1}$, as reported by Schaffrath \& Meacock (1995).

\section{RESULTS}

\section{Use of KITRP1 for selection of recombinant linear plasmids}

We wished to develop a second genetic marker that could be used for in vivo manipulation of the linear DNA killer plasmids of $K$. lactis. Thus, using an approach similar to previous work (Kämper et al., 1991) the transfer vector pAR5 was constructed (Fig. 1). Plasmid pAR5 carries homologous $\mathrm{k} 1$ segments identical to PAR 1 but employs the $K$. lactis TRP1 gene fused in-phase to the UCS element of k1ORF2 (k1UCS2) rather than $S$. cerevisiae LEU2 (Table 2; Schaffrath et al., 1992). This new marker gene is different in size to the previous ScLEU2-based marker allowing easy identification of recombinant linear plasmids. More significantly, these two markers can be used together in strain AWJ137, which carries chromosomal leu 2 and $\operatorname{trp} 1$ mutations, for procedures requiring two independent manipulations of the plasmid system.

It was therefore important to establish that the $\operatorname{trp} 1$ mutation of strain AWJ137 had a sufficiently low reversion frequency that recombinant linear plasmids could be selected and segregated by selection for k1UCS2KITRP1 marker in a similar manner to the ScLEU2 marker. Thus, DNA of plasmid pAR5, completely digested with NbeI and EcoRI, was used to transform the $\mathrm{k} 1 / \mathrm{k} 2$-carrying strain AWJ137 to tryptophan prototrophy. $\operatorname{Trp}^{+}$transformants were obtained at high 


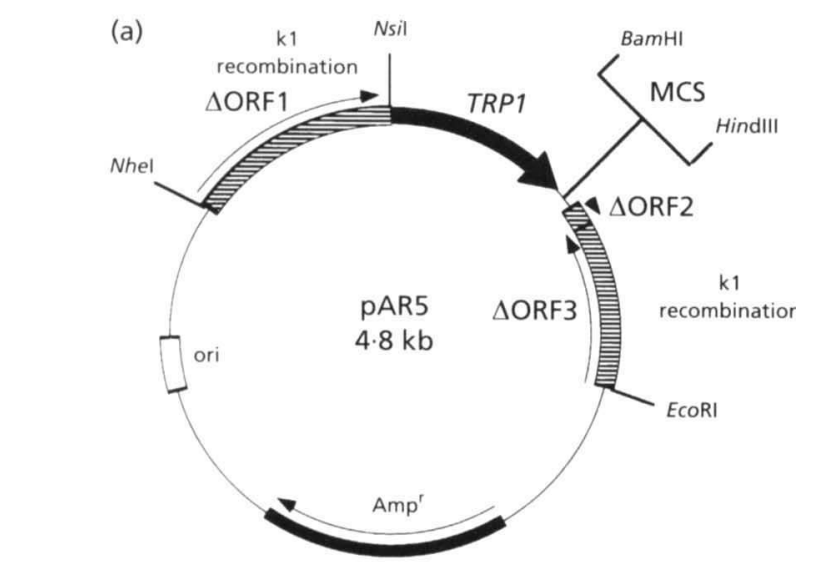

Table 3. Frequencies of $k 1$ and $k 2$ gene targeting

\begin{tabular}{|c|c|c|c|}
\hline $\begin{array}{l}\text { Target } \\
\text { gene }\end{array}$ & Vector & $\begin{array}{c}\text { Frequency } \\
\text { [( } \mu \text { g vector } \\
\left.\text { DNA })^{-1}\right]\end{array}$ & Hybrid* \\
\hline k1ORF2 & pAR5 & $260-430$ & pRKL1(100) \\
\hline k2ORF6 & pMS600 & $230-290$ & $\mathrm{rk} 2 / 6(100)$ \\
\hline k2ORF2 & pMS202 & $140-170$ & $\mathrm{rk} 2 / 2(96)$ \\
\hline
\end{tabular}

* Percentage of transformants carrying hybrid plasmid is in parentheses.
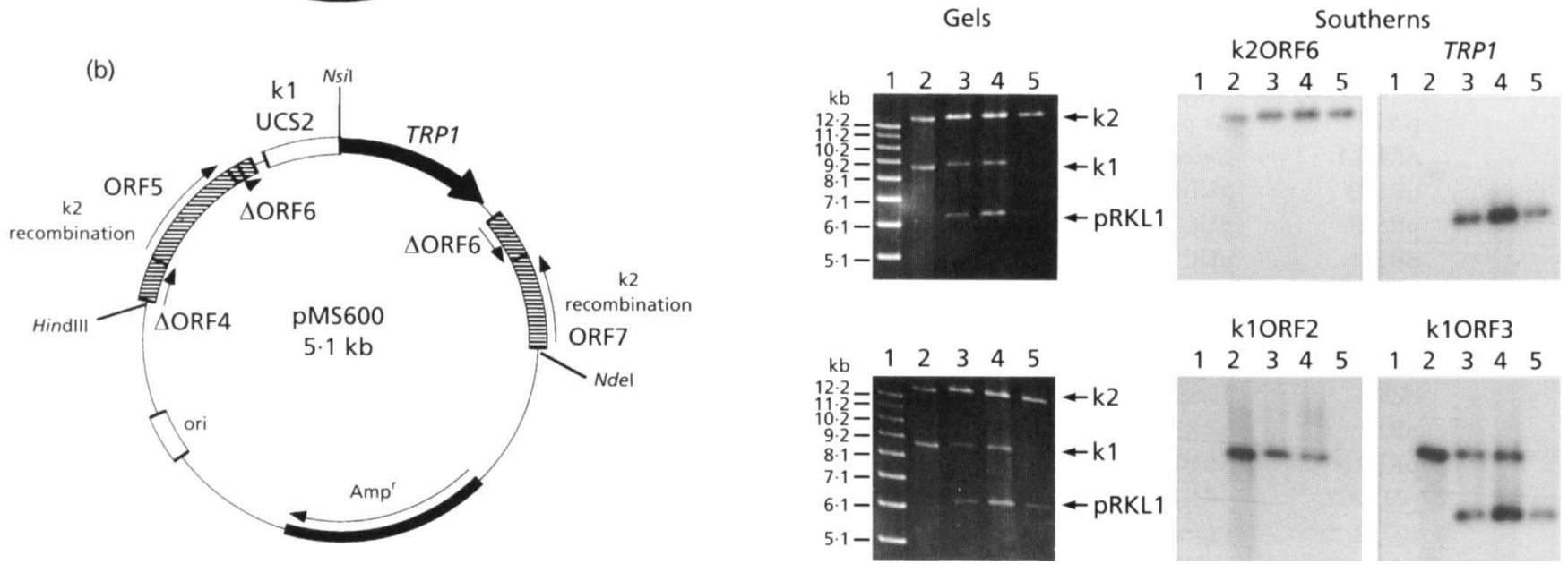

(c)

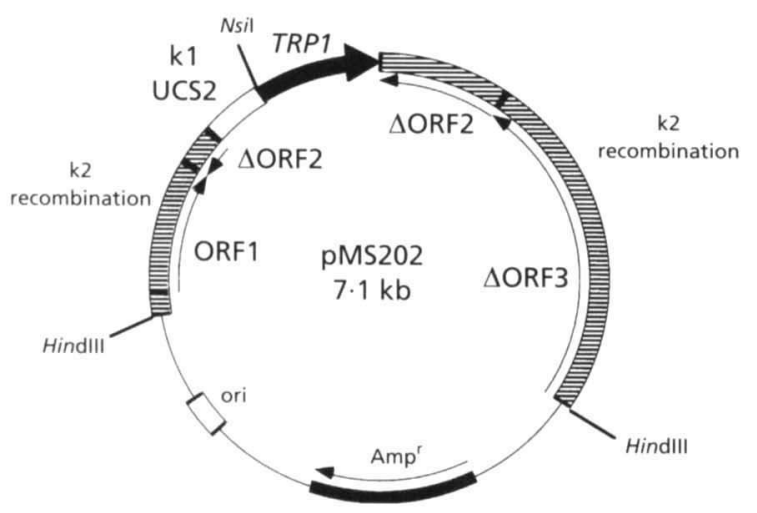

Fig. 2. Demonstration of k1ORF2 disruption in plasmid pRKL1. Linear plasmid DNA preparations from wild-type strain AWJ137 (lane 2) and pRKL1-harbouring strain MS1 grown for 25, 50 and 150 g.p.r. (lanes 3-5) were separated on agarose gels and hybridized with gene probes as indicated. Migration positions of linear plasmids k1, k2 and pRKL1 are indicated by arrows. Molecular mass markers (lane 1) were the $1 \mathrm{~kb}$ ladder (Gibco, BRL).

predicted (Fig. 2). Strain MS1 was subjected to prolonged cultivation in the absence of tryptophan to select for cells carrying pRKL1. As shown in Fig. 2, segregation of parental $\mathrm{k} 1$ from the hybrid pRKL1 was observed, eventually leading to complete loss of $\mathrm{k} 1$ over a growth period of 150 generations post-recombination (g.p.r.). Hybridization with radiolabelled probes made from k2ORF6, the KITRP1 gene, and the k1-derived ORF2 and ORF3 (Fig. 2), produced no signals corresponding to parental $\mathrm{k} 1$; only $\mathrm{pRKL} 1$ and $\mathrm{k} 2$ were maintained in the segregant strain, termed NKMS1. Thus, pRKL1 was able to displace wild-type $\mathrm{k} 1$, indicating the TRP1 selection regime to be successful in conjunction with the genetic background of strain AWJ137.

\section{Transcriptional analysis of k2ORF2 and k2ORF6}

frequencies (Table 3 ) and 48 randomly selected clones were all found to carry a new plasmid, termed pRKL1, in addition to $\mathrm{k} 1$ and $\mathrm{k} 2$. Southern blot hybridization analysis of one representative clone, MS1, revealed pRKL1 to have ORF2 replaced by the TRP1 gene as

Total RNA from both plasmid-containing and plasmidfree $K$. lactis strains was subjected to Northern analysis using k2 DNA fragments from within the ORF2 and 


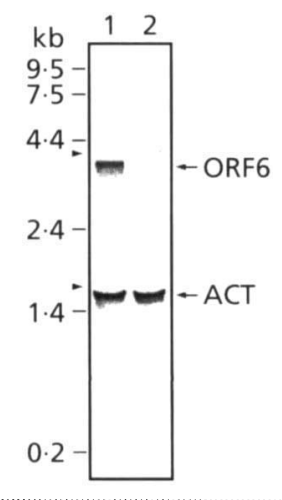

Fig. 3. Analysis of k2ORF6 transcription. Northern blot analysis of total RNA ( $20 \mu \mathrm{g}$ per lane) extracted from the k1/k2-carrying strain AWJ137 (lane 1) and k1/k2-free strain SD801 (lane 2). Hybridization probes were the $K$. lactis-specific actin and ORF6 DNA fragments (see Methods). Arrowheads indicate positions of the 265 and 185 yeast rRNAs and sizes of co-migrated RNA markers are indicated. Positions of the actin and ORF6 transcripts are indicated.

ORF6 coding regions as hybridization probes. As shown in Fig. 3, this analysis revealed a single transcript for ORF6 of estimated size $3.1 \mathrm{~kb}$ which was undetectable in RNA from plasmid-free cells. For ORF2, only a weak hybridization signal was detected indicating a less abundant transcript of $3.2 \mathrm{~kb}$ (data not shown). Comparison of ORF6 and actin mRNA levels in exponential-phase cultures indicates an overall low cellular transcription of the putative RNA polymerase gene when relative gene copy levels, one for actin versus many for the plasmidborne k2ORF6, are taken into account (Fig. 3).

\section{Disruption of k2ORF6}

The novel TRP1 marker described above was used to construct pMS600, a k2ORF6 disruption vector (Fig. 1b). In pMS600, the UCS-TRP1 fusion gene is bracketed by segments homologous to $k 2$ which include short remnants of the $5^{\prime}$ and $3^{\prime}$ terminal regions of ORF6. Thus, allelic replacement of ORF6 by the TRP1 marker gene should occur following homologous recombination between native $\mathrm{k} 2$ and the disruption cartridge; this will result in formation of $\mathrm{ORF} 6^{0}$ deletion plasmids. Wild-type killer strain AWJ137 was transformed with a HindIII/NdeI digest of pMS600 and $\operatorname{Trp}^{+}$clones were obtained at high frequency (Table 3). Plasmid analysis revealed that a new plasmid, termed $\mathrm{rk} 2 / 6$, was present in addition to $\mathrm{k} 1$ and $\mathrm{k} 2$ in all 48 independent isolates examined. Southern blot analysis of one representative transformant, designated as MS60, showed that in $\mathrm{rk} 2 / 6$ the TRP 1 marker had replaced the putative RNA polymerase gene ORF6 (Fig. 4). Moreover, $\mathrm{rk} 2 / 6$ was identified as a $\mathrm{k} 2$-derivative by hybridization to the $\mathrm{k} 2 \mathrm{ORF} 2$ probe and was found to carry the k1UCS2 element (Fig. 4). Long-term selection for TRP 1 failed to favour establishment of hybrid $\mathrm{rk} 2 / 6$ over k2. Even after 350 g.p.r., strain MS60 was still found to contain both $\mathrm{k} 2$ and the recombinant plasmid (Fig. 4);
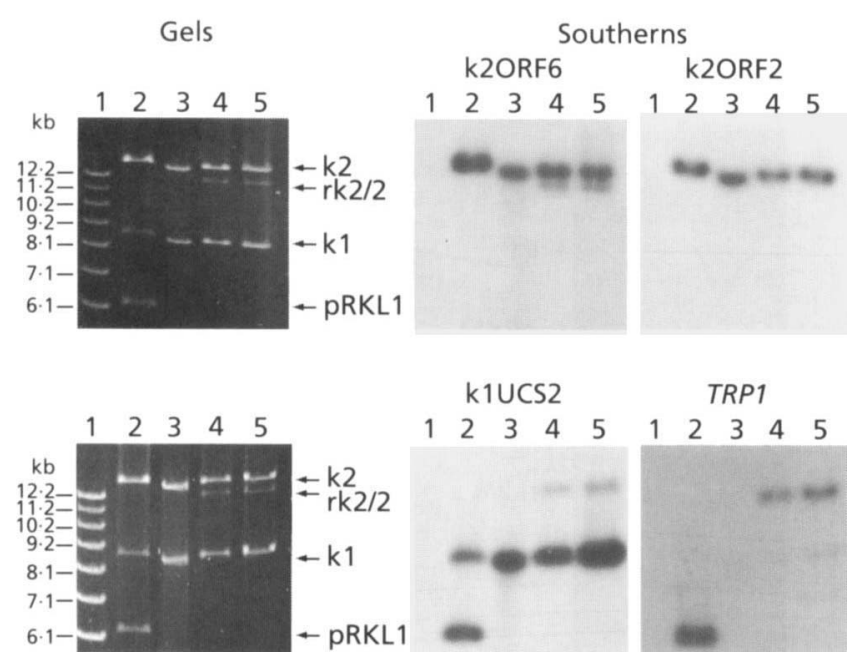

Fig. 4. Demonstration of k2ORF6 disruption in plasmid rk2/6. Linear plasmid DNA preparations from wild-type strain AWJ137 (lane 3) and rk2/6-carrying strain MS60 grown for 150 and 350 g.p.r. (lanes 4-5) were separated on agarose gels and hybridized to gene probes as indicated. Strain MS1 carrying pRKL1 (lane 2) served as positive control for the k1UCS2-TRP1 gene. Migration positions of linear plasmids k1, k2, rk2/6 and pRKL1 are indicated by arrows. Molecular mass markers (lane 1), were the $1 \mathrm{~kb}$ ladder (Gibco, BRL).

no apparent copy number changes could be detected as judged from intensities of plasmid bands on agarose gels. Thus, in contrast to the plasmid pair $\mathrm{k} 1 / \mathrm{pRKL} 1$ (see above), plasmid segregation and displacement of $\mathrm{k} 2$ by $\mathrm{rk} 2 / 6$ was not detectable even though the same selection marker was used. Therefore, maintenance of the ORF6 ${ }^{\circ}$ deletion plasmid $\mathrm{rk} 2 / 6$ appeared to be strictly dependent on the presence of wild-type $\mathrm{k} 2$, indicating that the putative RNA polymerase target gene represents an essential locus for plasmid functionality.

\section{Disruption of k2ORF2}

In an approach similar to that for ORF6, we next constructed transfer vector pMS202 for disruption of the putative DNA polymerase gene ORF2 on $\mathrm{k} 2$. The UCS-TRP1 fusion gene of pMS202 is placed in opposite polarity to ORF2 and flanked by k2 segments including remnant $3^{\prime}$ and $5^{\prime}$ terminal fragments of ORF 2 to promote recombination with parental $\mathrm{k} 2$ and formation of ORF2 deletion plasmids in vivo. Transformation of AWJ137, with HindIII-cut pMS202, to tryptophan prototrophy yielded $\mathrm{Trp}^{+}$clones at high frequency (Table 3 ), and 46 out of 48 transformants analysed for plasmid patterns were found to carry a novel plasmid, termed $\mathrm{rk} 2 / 2$ (data not shown). Southern hybridization analyses confirmed the expected structure of $\mathrm{rk} 2 / 2$; positive hybridization was found using probes specific for k2ORF6, k1UCS2 and TRP1 (Fig. 5), whereas no hybridization to the central ORF2-spanning probe (Fig. 5) was detected. Thus, we concluded that $\mathrm{rk} 2 / 2$ had undergone the expected structural changes during recombination leading to ORF2 

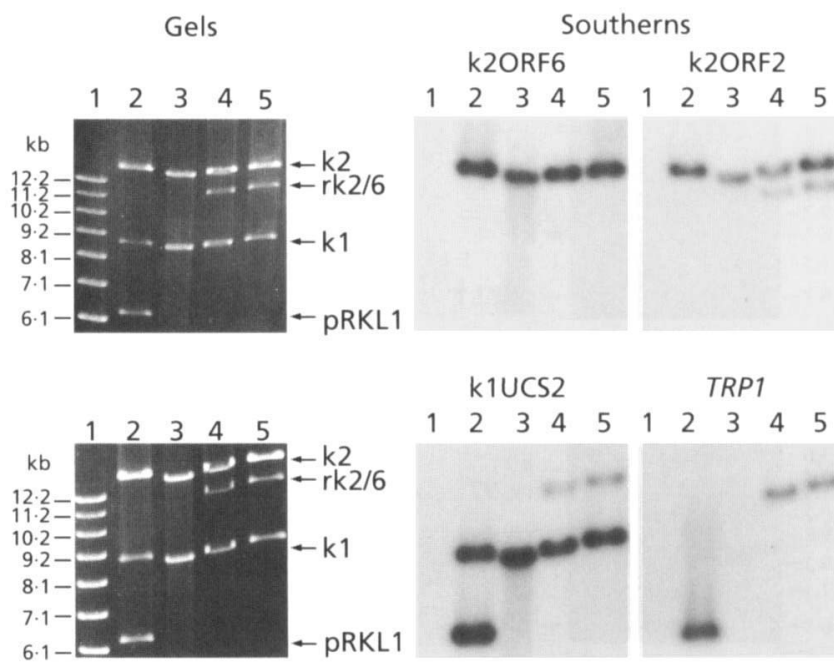

TRP1

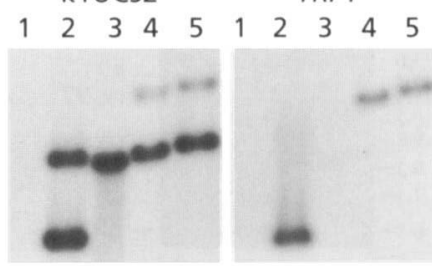

Fig. 5. Demonstration of k2ORF2 disruption in plasmid rk2/2. Linear plasmid DNA preparations from wild-type strain AWJ137 (lane 3) and rk2/2-carrying strain MS20 grown for 150 and 350 g.p.r. (lanes 4-5) were separated on agarose gels and hybridized to gene probes as indicated. Strain MS1 carrying pRKL1 (lane 2) served as positive control for the k1UCS2-TRP1 gene. Migration positions of linear plasmids k1, k2, rk2/2 and pRKL1 are indicated by arrows. Molecular mass markers (lane 1) were the $1 \mathrm{~kb}$ ladder (Gibco, BRL).

allelic replacement by the UCS-TRP1 marker. Prolonged cultivation under selective pressure of a representative transformant, designated MS20, revealed plasmid segregational behaviour comparable to that seen for ORF6 disruption; as is the case with $\mathrm{rk} 2 / 6$, the ORF2 deletion plasmid $\mathrm{rk} 2 / 2$ was unable to displace wild-type k2 under selective growth conditions. Again, relative copy numbers appeared to be unaffected at both 150 and 350 g.p.r., respectively (Fig. 5) with rk2/2 levels predominantly low compared to wild-type $k 2$. Thus, we concluded that ORF2 encodes an essential function involved in plasmid replication and/or maintenance.

\section{Physical characterization of hybrid $\mathbf{k} 2$ deletion plasmids}

Plasmids $\mathrm{rk} 2 / 2$ and $\mathrm{rk} 2 / 6$ were isolated from strains MS20 and MS60, respectively, by electroelution of proteinase K-treated DNA samples. Restriction mappings confirmed that $\mathrm{k} 2$ had undergone the predicted in vivo structural changes that resulted in generation of hybrid plasmids $\mathrm{rk} 2 / 2$ and $\mathrm{rk} 2 / 6$ (data not shown). As summarized in Fig. 6, new $S_{s t} \mathrm{I}$ and Bam HI sites were introduced into $\mathrm{rk} 2 / 2$ and $\mathrm{rk} 2 / 6$ by homologous recombination resulting in plasmid restriction patterns distinguishable from that of parental plasmid $\mathrm{k} 2$ and confirming the linear structure of both hybrids. Thus, both $\mathrm{rk} 2 / 2$ and $\mathrm{rk} 2 / 6$ are co-linear in genome organizations with $\mathrm{k} 2$ except for deletion of the ORF2 and ORF6 regions by replacement with the UCS-TRP1 marker gene. Both $\mathrm{rk} 2 / 2$ and $\mathrm{rk} 2 / 6$ have decreased sizes $\mathrm{rk} 2 / 2(12 \cdot 3 \mathrm{~kb})$
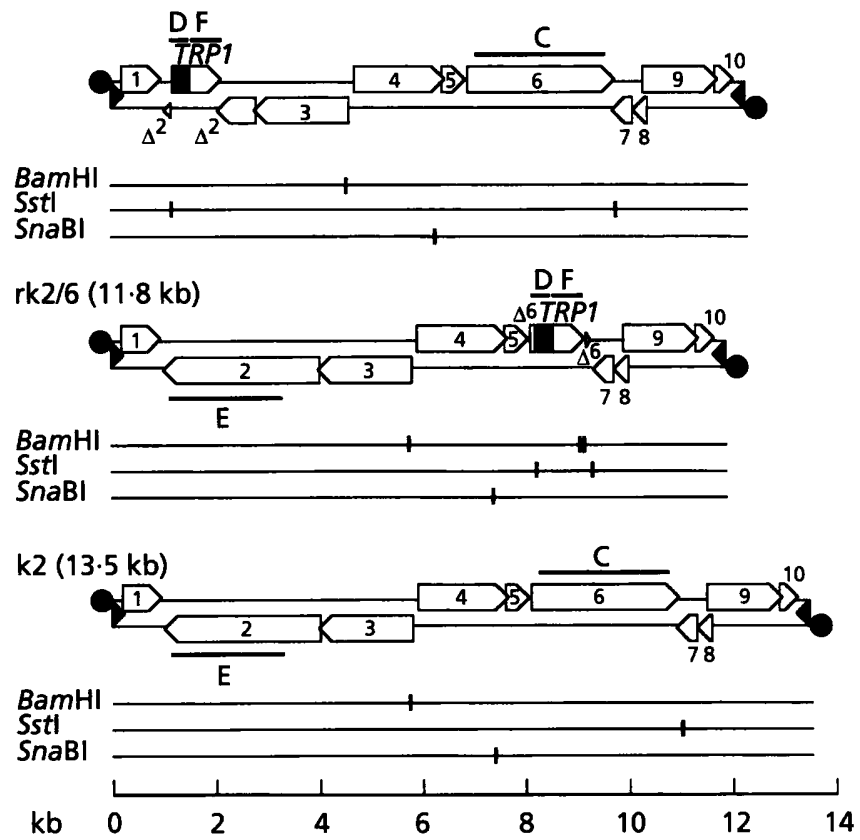

Fig. 6. Co-linearity of hybrid plasmids $r k 2 / 2$ and $r k 2 / 6$ with parental k2. The physical maps shown for rk2/2, rk2/6 and rk2 were obtained from Southern hybridization analyses of restriction digests involving electro-eluted DNA substrates and radioactive probes as follows: (a) k1UCS2, (b) KITRP1, (c) k2ORF6 and (d) k2ORF2. Restriction enzyme cleavage patterns are given below each map. Numbering of ORFs and k2, rk2/2 and $\mathrm{rk} / 2 / 6$ genome nomenclature are adopted from Tommasino et al. (1988); positions and polarities of ORFs and the TRP1 gene are indicated by open arrows. The k1UCS2 element driving TRP1 is indicated by a black bar. TIRs and TPs of the plasmids are presented as black triangles and black circles, respectively. The remainders of ORF2 in rk2/2 and ORF6 in rk2/6 are indicated by $\triangle$.

(12.3 and $11.8 \mathrm{~kb}$, respectively) when compared to parental k2 (13.5 kb) (Fig. 6).

\section{Relative plasmid copy number and stability}

We examined whether the hybrid plasmids were less stably maintained when ORF2 and ORF6 had been deleted. The recombinant plasmids $\mathrm{rk} 2 / 2$ and $\mathrm{rk} 2 / 6$ in MS20 and MS60 had reduced stabilities in comparison to wild-type $\mathrm{k} 2$ in cultures grown without selection for tryptophan prototrophy. In each case, all 200 colonies obtained after sequentially subculturing in YPD rich medium for 350 generations, were found to be $\operatorname{Trp}^{-}$as a result of having lost the hybrid plasmid $\mathrm{rk} 2 / 2$ or $\mathrm{rk} 2 / 6$ (data not shown). Thus, integration of TRP1 into ORF2 and ORF6 decreased the stability of the resulting recombinant plasmids. To assess relative plasmid copy numbers of the recombinant $\mathrm{k} 2$ plasmids versus wild-type $\mathrm{k} 1$ and $\mathrm{k} 2$ in cultures grown with $\operatorname{Trp}^{+}$selection, we carried out Southern hybridization analysis using $\mathrm{k} 1$ - and $\mathrm{k} 2$-derived gene probes and quantified the abundance of each plasmid with a Phosphor-Imager (Fig. 7). Plasmid copy numbers of $\mathrm{rk} 2 / 2$ and $\mathrm{rk} 2 / 6$ were significantly reduced in comparison to the k2ORF1 deletion plasmid pRKL2 

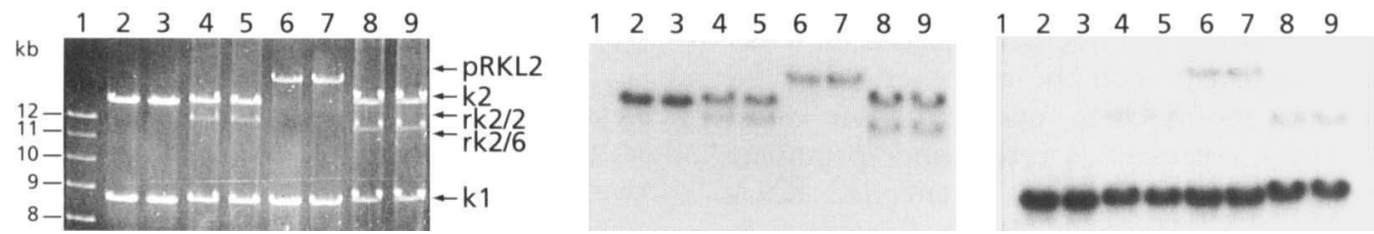

Fig. 7. Plasmid copy-number analysis. Linear plasmid DNA preparations from wild-type killer strain AWJ137 and various k2ORF-deletion strains were separated on agarose gels and hybridized to gene probes as indicated. Lanes: 1, molecular mass markers; 2-3, wild-type AWJ137; 4-5, k2ORF2 deletion strain MS20; 6-7, k2ORF1 deletion strain KRS13; 8-9, k2ORF6 deletion strain MS60. Growth for MS20, MS60 and KRS13 was 350 g.p.r. To determine the extent of hybridization of hybrid plasmids to the probes, relative band intensities were quantified using a Molecular Dynamics Phosphor-Imager and wild-type plasmids k1 and k2 from AWJ137 as internal controls (see Table 4). Migration positions of linear plasmids $\mathrm{k} 1, \mathrm{k} 2, \mathrm{rk} 2 / 2, \mathrm{rk} 2 / 6$ and $\mathrm{PRKL} 2$ are indicated by arrows.

(Schaffrath et al., 1992). Relative copy numbers were lower for hybrid $\mathrm{rk} 2 / 2$ than $\mathrm{rk} 2 / 6$, implying direct involvement of the ORF2 product in plasmid replication and an indirect maintenance function for ORF6 (Fig. 7). For the ORF6 mutant strain MS60, levels of all linear plasmids in the cell appeared to be generally affected, whereas the ORF2 deletion strain MS20 appeared to possess normal levels of wild-type $\mathrm{k} 1$ and $\mathrm{k} 2$ (Fig. 7). Table 4 summarizes the results from seven independent experiments using duplicate plasmid samples of AWJ137, MS20 and MS60 (data not shown); rk2/2 was found to have a sevenfold lower copy number relative to wild-type $\mathrm{k} 2$, whereas $\mathrm{rk} 2 / 6$ was reduced only fourfold compared to wild-type $\mathrm{k} 2$ copy numbers.

\section{Table 4. Relative plasmid copy numbers}

Determined by measurement of hybridization strength using a Molecular Dynamics Phosphor-Imager. In each strain, recombinant plasmids were monitored against copy levels of a wild-type plasmid carrying the same hybridization target sequence. Thus, the wild-type plasmid was assigned a value of 1 and the recombinant plasmid a copy level value proportional to the strength of the hybridization signal.

\begin{tabular}{|llll|}
\hline Strain & Plasmid & \multicolumn{2}{c|}{$\begin{array}{c}\text { Hybridization } \\
\text { probes }\end{array}$} \\
\cline { 3 - 4 } & & k1UCS2 & k2ORF4 \\
\hline AW J137 & $\mathrm{k} 1$ & 1 & \\
MS60 & $\mathrm{k} 2$ & & 1 \\
& $\mathrm{k} 1$ & 1 & 1 \\
& $\mathrm{k} 2$ & & $0 \cdot 24$ \\
MS20 & $\mathrm{rk} 2 / 6$ & $0 \cdot 25$ & 1 \\
& $\mathrm{k} 1$ & 1 & $0 \cdot 15$ \\
& $\mathrm{k} 2$ & & $0 \cdot 13$ \\
\hline
\end{tabular}

\section{DISCUSSION}

We report here the genetic analysis of ORF2 and ORF6 of the cytoplasmic linear killer plasmid $\mathrm{k} 2$ of $K$. lactis. Our data show these ORFs to be transcriptionally active genes essential for the linear plasmid system.

As with previous studies on the k1ORF2 and k2ORF1 deletion plasmids pJKL1 and pRKL2 (Kämper et al., 1991; Schaffrath et al., 1992), in vivo generation of hybrid plasmids pRKL1, rk2/2 and $\mathrm{rk} 2 / 6$ occurred at frequencies approaching $100 \%$. Thus, plasmid recombination is a highly specific process unlike the high level of nonhomologous recombination events seen for nuclear gene targeting in K. lactis (Stark \& Milner, 1989; Meinhardt \& Holtwick, 1995). Plasmid gene targeting at reproducibly high frequencies presumably reflects a copy-numberdependence comparable to recent recombination studies in S. cerevisiae (Wilson et al., 1994). Whether plasmid recombination is dependent on nuclear functions, such as those of the $R A D$ genes, or takes place in the cytoplasm by an alternative mechanism, has to await further detailed studies and isolation of $K$. lactis $\mathrm{R} A D$ mutants as described for $S$. cerevisiae (Dunderdale \& West, 1994).

Both k2ORF2 and ORF6 partially overlap with other upstream ORFs, ORF3 and ORF5, respectively, on the same DNA strand (Tommasino et al., 1988). However, Northern blot analysis revealed only single ORF2 and ORF6 transcripts of approximately $3 \cdot 2$ and $3 \cdot 1 \mathrm{~kb}$. Thus, both genes are probably transcribed as monocistronic units implying the existence of a mechanism that terminates ORF3 and ORF5 transcription while allowing ORF2 and ORF6 transcription to occur.

The novel UCS marker gene fusion used in this study, k1UCS2-TRP1, provides further substantial evidence for the existence of a plasmid-specific transcription system. Not only were we able to use this construct to generate the $\mathrm{k} 1 \mathrm{ORF} 2$ deletion plasmid pRKL1, but we were also able to demonstrate its use in $\mathrm{k} 2$ gene disruptions. Thus, in vivo formation of the $\mathrm{k} 2 \mathrm{ORF} 2$ and $\mathrm{k} 2 \mathrm{ORF} 6$ deletion plasmids $\mathrm{rk} 2 / 2$ and $\mathrm{rk} 2 / 6$ could be successfully selected 
by use of the TRP1 marker gene. Our results together with prevous studies on the k2ORF1 deletion plasmid pRKL2 (Schaffrath et al., 1992) show that a k1-derived UCS element is functionally active when placed onto $\mathrm{k} 2$. This is entirely consistent with the hypothesis that the conserved sequence motif, UCS, found upstream of all linear plasmid genes, represents a cytoplasmic promoter that is recognized by the putative k2-encoded RNA polymerase (Wilson \& Meacock, 1988; Romanos \& Boyd, 1988). Also consistent with this are recent reporter gene fusions showing the UCS5 motif of $\mathrm{k} 2$ to be an essential cis-acting element for foreign gene expression (Meinhardt et al., 1994; Schaffrath \& Meacock, 1995).

Our data on successful plasmid segregation of pRKL1 from $k 1$, resulting in pure recombinant $p R K L 1 / k 2$ constellations as in segregant NKMS1, are very similar to results obtained with k1ORF2 and k2ORF1 deletion plasmids pJKL1 and pRKL2 (Kämper et al., 1991; Schaffrath et al., 1992). These derivatives were also able to displace their parental wild-type plasmids, $\mathrm{k} 1$ and $\mathrm{k} 2$, respectively. Plasmid segregation as a consequence of progressive copy number decrease of the wild-type plasmid versus the recombinant during selective growth implies competition between hybrid and parental plasmids for rate-limiting maintenance factors, perhaps the $k 1 / k 2$ TPs, and an overall randomness in the choice of molecules for plasmid replication and/or partitioning.

In the cases of the ORF2- and ORF6-deletion plasmids $\mathrm{rk} 2 / 2$ and $\mathrm{rk} 2 / 6$, their failure to displace $\mathrm{k} 2$, even over a period of 350 generations of selective growth postrecombination, implies that both genes are required for plasmid functionality. This is a similar situation to that observed with k2ORF5 (Schaffrath \& Meacock, 1995). The inability of $\mathrm{rk} 2 / 2$ to displace $\mathrm{k} 2$ is particularly interesting since these cells contained plasmid $\mathrm{k} 1$ which also encodes a putative DNA polymerase ( $k 1 O R F 1)$. Therefore, we conclude that the k1ORF1-encoded DNA polymerase is unable to complement the defect arising by deletion of the k2ORF2-encoded DNA polymerase. We interpret this to mean that these two DNA polymerases are each specific for the plasmid that encodes them. Presumably this specificity resides in the recognition of the relevant TP/TIR structures for replication initiation. A similar interpretation can be drawn from the behaviour of pk129L/S, k1-hybrids deleted in the ORF1 putative k1 DNA polymerase structural gene (Fukuhara, 1987; Kitada \& Gunge, 1988), which cannot be maintained without the presence of a fully functional k1ORF1 in the same cell despite the presence of $k 2$.

Interestingly, relative plasmid copy levels of $\mathrm{k} 2$ and the recombinant plasmids remained unaffected during selective growth; $\mathrm{rk} 2 / 2$ had a lower copy level relative to wildtype $k 2$ than did $r k 2 / 6$. This may reflect the amount of each gene product necessary for the plasmid system to function. Thus, we propose direct involvement of the ORF2 product in $\mathrm{k} 2$ replication and an indirect $\mathrm{k} 1 / \mathrm{k} 2$ maintenance function for the putative ORF6-encoded RNA polymerase. This provides further evidence of the fundamental role played by $\mathrm{k} 2$ in the integrity and maintenance of the overall killer plasmid system.

\section{ACKNOWLEDGEMENTS}

We would like to thank Drs F. Meinhardt and J. J. Rossi for providing plasmids pAR4 and pACT3, respectively. This work was supported by a research studentship to S.M.S. from the Agriculture and Food Research Council, and by research grants to P. A.M. from the Science and Engineering Research Council (GR/H97642 \& GR/J57766) and constitutes part of a PhD thesis (R.S.), Department of Genetics, University of Leicester.

\section{REFERENCES}

Bolen, P. L., Eastman, E. M., Cihak, P. L. \& Hayman, G. T. (1994). Isolation and sequence analysis of a gene from the linear DNA plasmid $\mathrm{pPac1-2}$ of Pichia acaciae that shows similarity to a killer toxin gene of Kluyveromyces lactis. Yeast 10, 403-414.

Cong, Y.-S., Yarrow, D., Li, Y.-Y. \& Fukuhara, H. (1994). Linear DNA plasmids from Picbia etchelsii, Debaryomyces bansenii and Wingea robertsiae. Microbiology 140, 1327-1335.

Deshler, J. O., Larson, G. P. \& Rossi, J. J. (1989). Kluyveromyces lactis maintains Saccharomyces cerevisiae intron-encoded splicing signals. Mol Cell Biol 9, 2208-2213.

Dunderdale, H. J. \& West, S. C. (1994). Recombination genes and proteins. Curr Opin Genet Dev 4, 221-228.

Feinberg, A. P. \& Vogelstein, B. (1983). A technique for radiolabeling DNA restriction endonuclease fragments to high specific activity. Anal Biochem 132, 6-13.

Fukuhara, H. (1987). The RF1 gene of the killer DNA of yeast may encode a DNA polymerase. Nucleic Acids Res 15, 10046.

Gietz, D., St Jean, A., Woods, R. A. \& Schiestl, R. H. (1992). Improved method for high efficiency transformation of intact yeast cells. Nucleic Acids Res 20, 1425.

Gough, J. A. \& Murray, N. E. (1983). Sequence diversity among related genes for recognition of specific targets in DNA molecules. J Mol Biol 166, 1-19.

Gunge, N., Tamaru, A., Ozawa, F. \& Sakaguchi, K. (1981). Isolation and characterization of linear deoxyribonucleic acid plasmids from Kluyveromyces lactis and the plasmid-associated killer character. $J$ Bacteriol 145, 382-390.

Gunge, N., Fukuda, K., Morikawa, S., Murakami, K., Takeda, M. \& Miwa, A. (1993). Osmophilic linear plasmids from the salt-tolerant yeast Debaryomyces bansenii. Curr Genet 23, 443-449.

Hishinuma, F. \& Hirai, K. (1991). Genome organisation of the linear plasmid PSKL isolated from Saccharomyces kluyveri. Mol \& Gen Genet 226, 97-106.

Hishinuma, F., Nakamura, K., Hirai, K., Nishizawa, R., Gunge, N. \& Maeda, T. (1984). Cloning and nucleic acid sequences of the linear DNA plasmids from yeast. Nucleic Acids Res 12, 7581-7597.

Kămper, J., Esser, K., Gunge, N. \& Meinhardt, F. (1991). Heterologous expression on the linear DNA killer plasmid from Kluyveromyces lactis. Curr Genet 19, 109-118.

Kitada, K. \& Gunge, N. (1988). Palindrome-hairpin linear plasmids possessing only part of the ORF1 gene of the yeast killer plasmid pGKL1. Mol \& Gen Genet 215, 46-52.

McNeel, D. G. \& Tamanoi, F. (1991). Terminal region recognition factor 1, a DNA binding protein recognizing the ITRs of the pGKL linear plasmids. Proc Natl Acad Sci US A 88, 11398-11402.

Meinhardt, F. \& Holtwick, R. (1995). Generation of a stable nonreverting $\mathrm{Leu}^{-}$mutant of Kluyveromyces lactis by gene disruption. Appl Microbiol Biotechnol 42, 734-737.

Meinhardt, F. \& Rohe, M. (1993). Extranuclear inheritance: linear protein-primed replicating genomes in plants and microorganisms. 
In Progress in Botany, vol. 54, pp. 334-357. Edited by H. D. Behnke, K. Esser, K. Kubitzki, M. Runge \& H. Ziegler. Berlin, Heidelberg $\&$ New York: Springer-Verlag.

Meinhardt, F., Kempken, F., Kămper, J. \& Esser, K. (1990). Linear plasmids among eukaryotes: fundamentals and application. Curr Genet 17, 89-95.

Meinhardt, F., Wodara, C., Larsen, M. \& Schickel, J. (1994). A novel approach to express a heterologous gene on Kluyveromyces lactis linear killer plasmids: expression of the bacterial aph gene from a cytoplasmic promoter fragment without in-phase fusion to the plasmid open reading frame. Plasmid 32, 318-327.

Rohe, M., Schrunder, J., Tudzinsky, P. \& Meinhardt, F. (1992). Phylogenetic relationships of linear, protein-primed replicating genomes. Curr Genet 21, 173-176.

Romanos, M. \& Boyd, A. (1988). A transcriptional barrier to expression of cloned toxin genes of the linear plasmid $k 1$ of Kluyveromyces lactis: evidence that native $\mathrm{k} 1$ has novel promoters. Nucleic Acids Res 16, 7333-7350.

Sambrook, J., Fritsch, E. F. \& Maniatis, T. (1989). Molecular Cloning: a Laboratory Manual, 2nd edn. Cold Spring Harbor, NY: Cold Spring Harbor Laboratory.

Sanger, F., Nicklen, S. \& Coulson, A. R. (1977). DNA sequencing with chain-terminating inhibitors. Proc Natl Acad Sci USA 74, 5463-5467.

Schaffrath, R. \& Meacock, P. A. (1995). Kluyveromyces lactis killer plasmid pGKL2: molecular analysis of an essential gene, ORF5. Yeast 11, 615-628.

Schaffrath, R., Stark, M. J. R., Gunge, N. \& Meinhardt, F. (1992). Kluyveromyces lactis killer system: ORF1 of pGKL2 has no function in immunity expression and is dispensable for killer plasmid replication and maintenance. Curr Genet 21, 357-363.

Schaffrath, R., Soond, S. M. \& Meacock, P. A. (1995). Cytoplasmic gene expression in yeast : a plasmid-encoded transcription system in Kluyveromyces lactis. Biochem Soc Trans 23, $128 \mathrm{~S}$.
Sherman, F. (1991). Getting started with yeast. Methods Enzymol 194, 3-21.

Stark, M. J. R. \& Boyd, A. (1986). The killer toxin of Kluyveromyces lactis: characterization of the toxin subunits and identification of the genes which encode them. EMBO J 5, 1995-2002.

Stark, M. J. R. \& Milner, J. S. (1989). Cloning and analysis of the Kluyveromyces lactis TRP1 gene: a chromosomal locus flanked by genes encoding inorganic pyrophosphatase and histone $\mathrm{H} 3$. Yeast 5, 35-50.

Stark, M. J. R., Boyd, A., Mileham, A. J. \& Romanos, M. A. (1990). The plasmid-encoded killer system of Kluyveromyces lactis: a review. Yeast 6, 1-29.

Tanguy-Rougeau, C., Chen, X. J., Wesolowski-Louvel, M. \& Fukuhara, H. (1990). Expression of a foreign $\mathrm{Km}^{\mathrm{R}}$ gene in a linear killer DNA plasmid in yeast. Gene $91,43-50$.

Tokunaga, T., Wada, N. \& Hishinuma, F. (1987). Expression and identification of immunity determinants on the linear DNA killer plasmids pGKL1 and pGKL2 in Kluyveromyces lactis. Nucleic Acids Res 15, 1031-1046.

Tommasino, M. (1991). Killer system of Kluyveromyces lactis: the open reading frame 10 of the pGKL2 plasmid encodes a putative DNA binding protein. Yeast 7, 245-252.

Tommasino, M., Ricci, S. \& Galeotti, C. (1988). Genome organisation of the plasmid pGKL2 from Kluyveromyces lactis. Nucleic Acids Res 16, 5863-5878.

Wilson, D. W. \& Meacock, P. A. (1988). Extranuclear gene expression in yeast: evidence for a plasmid-encoded RNA polymerase of unique structure. Nucleic Acids Res 16, 8097-8112.

Wilson, J. H., Leung, W. Y., Bosco, G., Dieu, D. \& Haber, J. E. (1994). The frequency of gene targeting in yeast depends on the number of target copies. Proc Natl Acad Sci US A 91, 177-181.

Received 6 April 1995; revised 8 June 1995; accepted 16 June 1995. 